\title{
A Comparison of Alternative Forecast Models of REIT Volatility
}

\author{
Jian Zhou*, Ph.D. \\ Assistant Professor \\ Department of Marketing and Consumer Studies \\ College of Management and Economics \\ University of Guelph \\ Guelph, ON N1G 2W1, Canada \\ E-Mail: jian@uoguelph.ca \\ Zhixin Kang, Ph.D. \\ Assistant Professor \\ University of North Carolina at Pembroke \\ One University Drive \\ Pembroke, NC 28372-1510, U.S.A. \\ E-Mail: zhixin.kang@uncp.edu
}

* Corresponding author. 


\begin{abstract}
This study compares the relative performance of several well-known models in the forecasting of REIT volatility. Overall our results suggest that long-memory models (ARFIMA \& FIGARCH) provide the best forecasts. Using either a large sample or some statistically justified small subsamples, we find that long memory models consistently outperform their short-memory counterparts (GARCH \& Stochastic Volatility models) over a variety of forecast horizons. We also find that asymmetric models (EGARCH \& FIEGARCH) are the worst performers among all models. Our study complements and extends a recent study of Cotter and Stevenson (2008) which demonstrates the usefulness of long-memory models in modeling REIT volatility. We conclude that in addition to modeling REIT volatility, long-memory models should also be adopted to forecast REIT volatility.
\end{abstract}

Keywords REIT Volatility · Forecasting $\cdot$ Short-memory model· Long-memory model 


\section{Introduction}

Real estate investment trusts (REITs) have evolved since the early 1990s to become an important asset class. As published by the National Association of Real Estate Investment Trusts (NAREIT), the market capitalization of real estate investment trusts (REITs) in the U.S. has grown from $\$ 8.7$ billion in 1990 , to $\$ 124.3$ billion in 1999 , and to $\$ 312$ billion in 2007 . Consequently, an increasing amount of research has been devoted to this asset class. In particular, substantial focus has been placed on analyzing the return characteristics of REITs and the relationship between REITs and the direct real estate markets and more broadly the capital market (e.g. Barkham and Geltner, 1995; Li and Wang, 1995; Ling and Naranjo, 1999; Liu et al. 1990; Liu and Mei, 1992; Mei and Lee, 1994; Myer and Webb, 1994; Seiler et al.1999, etc.). In contrast, the literature on the volatility behavior of REIT returns remains very thin. Only a few papers have examined issues related to REIT volatility. For instance, Devaney (2001) studied the sensitivity of REIT returns and volatility to interest rates. Bredin et al. (2007) analyzed how unanticipated changes in the Fed Funds rates affect REIT volatility. Stevenson (2002) explored volatility spillovers across different REIT sectors and between REITs and the equity and fixedincome sectors. Winniford (2003) investigated the seasonality in REIT volatility. Cotter and Stevenson (2006) examined the return and volatility linkages both within the REIT sectors and between REITs and mainstream equities. Cotter and Stevenson (2008) tested for the persistence or long memory in REIT volatility.

An understanding of REIT volatility is very important to academics, policy makers, and investors. This is because volatility, as a measure of risk, plays a critical role in portfolio 
diversification, derivatives pricing, hedging and financial risk management. REIT, due to its significant growth in market capitalization and trading volume, has received greater attention from security analysts and pension fund managers in the execution of their investment plans. For example, REIT has become a popular investment vehicle to be included in a well-diversified portfolio because of its improved liquidity and imperfect covariance with publicly traded equities and bonds (Chandrashekaran, 1999). Because expectations are always important for making investment decisions, the success of the aforementioned investment activities depends on our ability to correctly predict volatility. As will be discussed later, REIT volatility has been increasing over time with the most pronounced upswing occurring in recent years. In light of this, the need for accurate volatility forecasts is expected to be growing. REITs have long been considered to be an asset class that gains its popularity through stable return and low volatility. But such a perception has been impacted due to the recent bout of high volatility. Those investors that have traditionally invested in the REIT sector now face challenges of how to minimize their risks in the current climate. One important input to their decision making is precise forecasts of REIT volatility, which is the subject of this study.

To our best knowledge, all existing studies have just concentrated on modeling REIT volatility. No one has yet attempted to forecast REIT volatility. This study aims to fill this void. Specifically, we want to identify, among a variety of models, which one is most appropriate to predict REIT volatility. The models examined here cover a varying degree of complexity, ranging from the GARCH-class models to the post-GARCH class of models. As for the GARCH-class models, we consider both a simple symmetric GARCH model and an asymmetric GRACH model (i.e. Exponential GARCH or EGARCH). Since the GARCH model has been 
extensively used in the literature to model time-varying conditional volatility of financial time series, it is treated as the benchmark model in this study. In addition to the GARCH-class models, we also consider post-GARCH class of models including the stochastic volatility (SV), Fractionally Integrated GARCH (i.e. FIGARCH), Fractionally Integrated Exponentially GARCH (i.e. FIEGARCH), and Fractional Integrated ARMA (i.e. ARFIMA). The SV model, proposed by Taylor (1982, 1986), provides an alternative formalization of the time-varying conditional volatility in comparison to the GARCH-class models. It differs from GARCH in that it models the conditional volatility as an unobserved component following a stochastic process whereas GARCH restricts conditional volatility to be a deterministic function of lagged squared residuals and lagged conditional volatility. The SV model has been found to outperform GARCH models in some applied forecasting situations (see, for example, So et al., 1999 and Yu, 2002). Hence, it is worthwhile to investigate the relative merits of SV models in forecasting REIT volatility. Besides the SV model, we also include FIGARCH, FIEGARCH, and ARFIMA into our comparisons. These models are commonly referred to as long memory models in the financial economics literature because in these models the autocorrelation in volatility exists at significant levels and persists over long lags. In contrast, the autocorrelation exhibits a fast decay pattern in those aforementioned models (GARCH, EGARCH \& SV). Hence these models are classified as short memory models. Long memory or persistence in volatility has been widely documented in the general financial literature and thus established as a stylized feature of asset volatility (see, for example, Anderson and Bollerslev, 1997a, 1997b; Baillie et al., 1996; Ding et al. 1993; Lobato and Savin, 1998). When it comes to the REIT sector, a recent study of Cotter and Stevenson (2008) confirmed that long-memory also exist in REIT volatility. Such a finding serves as further motivation for us to examine how long memory models fare in forecasting 
REIT volatility. To this end, we consider three models-FIGARCH, FIEGARCH, and ARFIMA. These models have been found to have considerable success in capturing the long memory feature of financial volatility (e.g. Baillie et al. 1996, Bollerslev and Mikkelsson 1996, Granger and Joyeux 1980).

To carry out the forecast comparisons, we use daily REIT total return indices obtained from FTSE for the period of 01/05/1999 to 04/30/2008. The forecasting accuracy is measured with traditional statistical criteria such as root mean squared error (RMSE) and mean absolute error (MAE). Six forecast horizons (1-, 5-, 10-, 15-, 20-, and 25-day-ahead) are tried. Overall our finding suggests that long memory models (ARFIMA \& FIGARCH) outperform their short memory counterparts (GARCH \& SV) in the forecasting of REIT volatility. More specifically, ARFIMA model provides the most accurate forecasts among all models. FIGARCH ranks second except at the 1-day horizon when it loses to SV. SV ranks third for all longer horizons (5day and beyond). Following SV is the fourth-ranked GARCH-the benchmark model in this study. Asymmetric volatility models (EGRACH \& FIEGARCH) rank last. This pattern of ranking holds for both evaluation criteria. To check on the robustness of our findings, we divide the full sample into three subsamples based on statistically justified break points in the proxies of REIT volatility process. We then conduct REIT volatility forecasting for each subsample. The results from all three subsamples are strikingly consistent with those from the full sample. That is, ARFIMA is the best performer at all forecast horizons and FIGARCH is the second best except at the 1-day forecast in subsample I at which it gets beat by SV and GARCH. So overall our study suggests that long memory models are superior to short memory models in predicting REIT volatility and this finding is independent of the sample size and forecast periods. The 
success of long memory models can be attributed to their ability to approximate the true data generating process of REIT volatility. As Poon (2005) pointed out, the performance of a volatility model depends on the characteristics of empirical data that it tries to capture and predict. Given the strong evidence of long memory found for REIT volatility here and in Cotter and Stevenson (2008), we believe that long memory is a genuine feature of REIT volatility. This helps to explain the superiority of long memory models in forecasting REIT volatility.

The reminder of this paper is organized as follows. The following section outlines the various models used to forecast REIT volatility. The third section presents the data. The empirical findings and their implications for financial practices are discussed in the fourth section. The final section concludes.

\section{Models for Forecasting REIT Volatility}

\section{1. $\operatorname{GARCH}(\mathrm{p}, \mathrm{q})$ Model}

In our analysis of forecasting REIT volatility, the benchmark model is the generalized autoregressive conditional heteroscedastic (GARCH) model proposed by Bollerslev (1986). GARCH models are particularly useful for modeling time-varying volatility and have been extensively used by both researchers and practitioners. It is well known that many financial time series display volatility clustering whereby volatility is likely to be high when it has recently been high and volatility is likely to be low when it has recently been low. GARCH models address the issue of volatility clustering by specifying the conditional variance to be linearly 
dependent on the past behavior of the squared residuals and a moving average of past conditional variances. Specifically, a GARCH(p, q) model assumes a form of:

$$
\begin{aligned}
& y_{t}=\sigma_{t} \varepsilon_{t}, t=1,2, \ldots, T \\
& \sigma_{t}^{2}=\alpha_{0}+\alpha_{1} y_{t-1}^{2}+\cdots+\alpha_{p} y_{t-p}^{2}+\beta_{1} \sigma_{t-1}^{2}+\cdots+\beta_{q} \sigma_{t-q}^{2}
\end{aligned}
$$

where $y_{t}$ is the demeaned return of a financial asset at time $t, \sigma_{t}$ is the instantaneous volatility of the return at time $t, \quad E_{t-1}\left(\varepsilon_{t}\right)=E_{t-1}\left(\varepsilon_{t}^{2}-1\right)=0, \quad T \quad$ is the sample size, $\alpha_{i}(i=0,1, . . p)$ and $\beta_{i}(i=0,1, . . q)$ are model parameters, $p$ is the maximum order of the $A R C H$ term, and $q$ the maximum order of the GARCH term.

\section{2. $\operatorname{EGARCH}(\mathrm{p}, \mathrm{q})$ Model}

The exponential GARCH (i.e. EGARCH) model is built upon the GARCH model with an intention to capture the asymmetric impacts of good news and bad news on volatility. It is well believed that negative innovations to the return may generate higher volatility than positive innovations of the same magnitude. This asymmetric effect, also referred to as leverage effect, led Nelson (1991) to introduce the EGARCH model with a specific variable that distinguishes between good news volatility and bad news volatility. An EGARCH (p, q) model takes the following form:

$$
\begin{aligned}
& y_{t}=\sigma_{t} \varepsilon_{t}, t=1,2, \ldots, T \\
& \log \left(\sigma_{t}^{2}\right)=\alpha_{0}+\left[1-\sum_{j=1}^{q} \beta_{j} B^{j}\right]^{-1}\left[1+\sum_{i=1}^{p} \alpha_{i} B^{i}\right] g\left(\varepsilon_{t-1}\right)
\end{aligned}
$$


where all variables and parameters are defined the same way as in the GARCH models, except that $B^{j}$ and $B^{i}$ are backshift operators defined as: $x_{t} B^{j}=x_{t-j}$, and $g\left(\varepsilon_{t}\right)=\lambda_{1} \varepsilon_{t}+\lambda_{2}\left(\left|\varepsilon_{t}\right|-E\left(\left|\varepsilon_{t}\right|\right)\right)$ with $\lambda_{1}$ and $\lambda_{2}$ being new parameters.

In the EGARCH $(p, q)$ model, if $\lambda_{1}$, the coefficient of $\varepsilon_{t}$, is negative, then bad news shocks will have a greater impact on volatility than good news shocks of the same magnitude.

\section{Stochastic Volatility (SV) Model}

The stochastic volatility (SV) model developed by Taylor $(1982,1986)$ provides an alternative way to model time-varying conditional volatility. In contrast to the GARCH-type models which restrict the time-varying volatility to be deterministically dependent on past information, the SV model treats the volatility as an unobserved component that follows a stochastic process. Volatility by nature is stochastic. Besides the past information such as lagged squared residuals and lagged conditional variances, many other factors like economic information, political information, and investors' behaviors would also affect volatility. Therefore, volatility is believed to contain some random components. The SV model explicitly includes an unobserved random shock into the characterization of the volatility dynamics and allows the volatility to follow some latent stochastic process. A basic stochastic volatility model is given below:

$$
\begin{aligned}
& y_{t}=\sigma_{t} \varepsilon_{t}, t=1,2, \ldots, T \\
& \sigma_{t}^{2}=\exp \left(h_{t}\right) \\
& h_{t}=\mu+\varphi h_{t-1}+\sigma_{\eta} \eta_{t}
\end{aligned}
$$

where all variables and parameters are defined the same way as in the GARCH models, except 
that $h_{t}$ is the logarithm of $\sigma_{t}^{2}, \eta_{t}$ is a white noise uncorrelated with $\varepsilon_{t}, \mu$ is a constant, $\varphi$ is a parameter representing the persistence in the log-volatility of $h_{t}$, and $\sigma_{\eta}$ is the volatility of $h_{t}$. In this model, $h_{t}$ is specified as a latent stochastic process and it follows a stationary process when $|\varphi<1|$, and $\eta_{t}$ stands for the random shock occurring to the log-volatility process.

The SV model is theoretically attractive but empirically challenging because the unobserved volatility process $\left(h_{t}\right)$ enters the model in a non-linear fashion which leads to the likelihood function without a closed-form solution (for a detailed discussion, see Ghysels et al. 1996 and Shephard 1996). A number of methods have been proposed to estimate the SV model. Such methods include quasi-maximum likelihood (QML) (Ruiz, 1994), simulated maximum likelihood (SML) (Danielsson, 1994), generalized method of moments (GMM) (Andersen and Sorensen, 1996), and Markov Chain Monte Carlo (MCMC) (Kim et al, 1998). The various methods differ in ease and speed of estimation. In this study, the MCMC method is chosen because it is simple to implement and reliable. We use the MCMC method to estimate the parameters $\left(\mu, \varphi, \sigma_{\eta}\right)$ and filter the unobserved volatility $\left\{\sigma_{t}^{2}\right\}_{t=1}^{T}$. Given the estimates- $(\hat{\mu}, \hat{\varphi}$, $\left.\hat{\sigma}_{\eta}\right)$ and $\left\{\hat{\sigma}_{t}^{2}\right\}_{t=1}^{T}$, we construct multi-step forecasts of the conditional volatility by the recursion $\hat{\sigma}_{T+k}^{2}=e^{\ln \left(\tilde{\sigma}_{T+k}^{2}\right)} e^{\hat{\sigma}_{\eta}^{2} / 2}$, where $\ln \left(\tilde{\sigma}_{T+k}^{2}\right)=\hat{\varphi}^{k} \ln \left(\hat{\sigma}_{T}^{2}\right)$

\section{4. $\operatorname{FIGARCH}(\mathrm{p}, \mathrm{q})$ Model}

As mentioned earlier, it has become a stylized fact that many financial time series display high persistence in their volatility. The autocorrelation in various measures of volatility exist at 
significant levels and persists over long lags. This property, also referred to as long memory in volatility, has been extensively documented in the financial economics literature (e.g. Anderson and Bollerslev, 1997a, 1997b; Baillie et al. 1996; Ding et al. 1993; Lobato and Savin, 1998). A recent study of Cotter and Stevenson (2008) also found strong evidence for long memory in REIT volatility. Therefore, it is worthwhile to explore whether long memory models produce better forecasts than the baseline GARCH model. To this end, the Fractionally Integrated GARCH (i.e. FIGARCH) model proposed by Baillie et al. (1996) is used here. A FIGARCH(p,q) model can be written as:

$$
\begin{aligned}
& y_{t}=\sigma_{t} \varepsilon_{t}, t=1,2, \ldots, T \\
& \left.\sigma_{t}^{2}=\alpha_{0}\left[1-\sum_{j=1}^{q} \beta_{j} B^{j}\right]^{-1}+\left\{1-\left[1-\sum_{j=1}^{q} \beta_{j} B^{j}\right]^{-1} \sum_{i=1}^{p} \alpha_{i} B^{i}(1-B)^{d}\right]\right\} y_{t}^{2}
\end{aligned}
$$

where all variables and parameters are defined the same way as in the GARCH models, except $B^{j}$ and $B^{i}$ are backshift operators defined as: $x_{t} B^{j}=x_{t-j}$, and $d$ is the fractional differencing parameter.

The FIGARCH(p,q) model captures the long memory feature of financial volatility through the fractional differencing parameter $(d)$. As shown in Baillie et al.(1996), for $0<d<1$ the conditional volatility $-\sigma_{t}^{2}$ will decay at a slow hyperbolic rate which is a typical symptom of long memory.

\section{5. $\operatorname{FIEGARCH}(\mathrm{p}, \mathrm{q})$ Model}

The FIGRACH model can be easily expanded to allow for asymmetric effects of good and bad 
news on volatility. The resulting model is called Fractionally Integrated Exponential GARCH (i.e. FIEGARCH). The FIEGARCH model was first proposed by Bollerslev and Mikkelsson (1996). A FIEGARCH(p,q) model is given below:

$$
\begin{aligned}
& y_{t}=\sigma_{t} \varepsilon_{t}, t=1,2, \ldots, T \\
& \log \left(\sigma_{t}^{2}\right)=\alpha_{0}+\left[1-\sum_{j=1}^{q} \beta_{j} B^{j}\right]^{-1}(1-B)^{-d}\left[1+\sum_{i=1}^{p} \alpha_{i} B^{i}\right] g\left(\varepsilon_{t-1}\right)
\end{aligned}
$$

where all variables and parameters are defined the same way as in the FIGARCH models, except

$d$ now is a real number in $(-0.5,0.5)$, and $g\left(\varepsilon_{t}\right)=\lambda_{1} \varepsilon_{t}+\lambda_{2}\left(\left|\varepsilon_{t}\right|-E\left(\left|\varepsilon_{t}\right|\right)\right)$ with $\lambda_{1}$ and $\lambda_{2}$ being new parameters. As in the EGARCH model, $\lambda_{1}$ measures the leverage effect. It is worth noting that in contrast to FIGARCH, $d$ here does not have to satisfy any nonnegative constraint in order to capture the long memory feature. As pointed out by Bollerslev and Mikkelsen (1996), $d$ only needs to satisfy: $d<1$ but $d \neq 0$. Note that $d=0$ implies the conventional EGARCH.

\section{ARFIMA Model}

The Fractionally Integrated ARMA (i.e. ARFIMA) model, introduced by Granger and Joyeux (1980) and Hosking (1981), presents a parametric alternative to modeling long-memory for financial time series. ARFIMA models originate from ARMA models and extend the ARMA models by introducing a fractional differencing parameter to account for the high persistence in time series. A prototypical ARFIMA model is given below:

$\Phi(B)(1-B)^{d} y_{t}=\Theta(B) \varepsilon_{t}$ 
where $y_{t}$ is the value of a financial time series at time $t, d$ is the fractional differencing parameter, $\Phi(B)=1-\phi_{1} B-\cdots-\phi_{p} B^{p}$ and $\Theta(B)=1-\theta_{1} B-\cdots-\theta_{p} B^{q}$ are the autoregressive and moving average polynomials in the lag operator $B$ respectively, and $\varepsilon_{t}$ is white noise.

The properties of the ARFIMA process depend on the value of the differencing parameter $d$. The process is stationary and invertible if $|d|<0.5$ while it becomes non-stationary if $|d| \geq 0.5$ as it has infinite variance. When $|d|<0.5$, the process is said to exhibit (i) long memory or longrange dependence if $0<d<0.5$; (ii) anti-persistence or long-range negative dependence if $-0.5<d<0$; and (iii) short memory if $d=0$ (in this case, ARFIMA reduces to ARMA). The parameters of the ARFIMA model can be estimated by exact maximum likelihood (Sowell, 1992) and the $k$-step ahead forecasts of $y_{t}$ can be computed from the AR representation of the process (see Brockwell and Davis, 1991).

The ARFIMA model differs from the FIGARCH and FIEGARCH models in that it is a conditional mean model in which only one equation is specified while for FIGRACH and FIEGARCH two equations are specified (one for the mean and the other for the variance). So in order for ARFIMA to be used to model the volatility process, the common practice is to first generate a measure of volatility and then plug it into the equation (namely, replaces $y_{t}$ ). For this purpose, we employ a popular measure of volatility - the squared returns of REITs. Apparently, this modeling strategy is different than that of the GARCH-type models in which the volatility is treated as unobserved and estimated from the asset returns. 


\section{Data}

The data for this study consists of daily total return indices (including dividends) for REIT. The data set is obtained from FTSE and covers the period from 01/05/1999 to 04/30/2008 with a total of 2363 observations. The daily total return indices are transformed into continuously compounded rates of returns, $r_{t}=100 * \ln \left(S_{t} / S_{t-1}\right)$, where $S_{t}$ is the end-of-day closing total return index and $S_{t-1}$ is the previous end-of-day closing index.

Figure 1 presents the time-series plot of daily returns. As shown in the figure, the returns are time varying with volatility clusters. It is also quite apparent that the volatility of REITs returns has been increasing over the sample period. Several factors are thought to contribute to the noticeable upswing in REIT volatility. One is the introduction of REIT-based derivatives. As Horng and Wei (1999) noted, we have witnessed increasing uses of derivatives in the REIT market in the last decade. ${ }^{1}$ These new financial tools have since been utilized by hedge funds and day traders to make profits. When they short-sell a stock or bet heavily on a company, the price of REITs can fluctuate greatly. As a result, we observe increased volatility. Two is the growth in the trading volume of REITs since 1990s. In the literature growing volume has been seen as an important driver for the increasing volatility. Lamoureux and Lastrapes (1990) explained that trading volume of stocks reflects the dependence in information flows to the market that feeds directly into price volatility. Cotter and Stevenson (2008) endorsed this point for the REIT market. Finally, as well documented in the literature (e.g. Nelson, 1989), the volatility of securities returns is also related to macroeconomic fluctuations in a way that high volatility usually occurs during economic downturns. As shown in Figure 1, the highest volatility arises 
towards the end of data sample. Obviously, this is caused by the ongoing subprime mortgage crisis and the consequent global financial crisis which is widely believed to dwarf any financial crises since World War II.

Table 1 reports some descriptive statistics of daily REIT returns. During the study period, REIT generates a positive average return of 0.00049 . The average return is very close to the median return. But the standard deviation of 1.04 is much higher. The REIT returns display some evidence of skewness and kurtosis. They are skewed slightly to the right, suggesting that positive returns are more likely to occur than negative returns. REIT returns also show significant excess kurtosis, indicating the presence of fatter tails in comparison with the standard normal distribution. A comparison between the density of REIT returns and normal distribution is displayed in Figure 2. ${ }^{2}$

\section{Empirical Results}

In order to evaluate the accuracy of forecasts produced by the different models, two popular measures - root mean square error (RMSE) and mean absolute error (MAE) are used. The two measures are defined as follows:

$R M S E=\sqrt{\frac{1}{M} \sum_{j=1}^{M}\left(\hat{\sigma}_{j}^{2}-\sigma_{j}^{2}\right)^{2}} \quad$ and $\quad M A E=\frac{1}{M} \sum_{j=1}^{M}\left|\hat{\sigma}_{j}^{2}-\sigma_{j}^{2}\right|$

where $\hat{\sigma}^{2}$ is the forecast of volatility, $\sigma^{2}$ is the true volatility, $M$ is the total number of forecasts. 
In practice, the true volatility $\left(\sigma^{2}\right)$ is unobserved. It remains an ongoing debate regarding the appropriate proxy of $\sigma^{2}$ with which to evaluate the forecasting performance for different models. In the empirical literature, some studies (e.g. Evans and McMillan, 2007; Yu, 2002) simply used the pre-estimated volatility from a model to proxy $\sigma^{2}$ and then plugged in the forecasts $\left(\hat{\sigma}^{2}\right)$ from the same model to compute RMSE and MAE. This practice is problematic because different models could lead to different proxies of $\sigma^{2}$. To avoid this problem, we adopt the method of Gospodinov et al. (2006) in which $\sigma^{2}$ is proxied by realized volatility (RV) and historical volatility (HV) calculated from REIT returns. By doing so, the forecasts from different models are compared to a common $\sigma^{2}$. Following their method, we construct a rolling sample for realized volatility from overlapping data using the expression

$R V_{t, \tau}=\frac{1}{\tau} \sum_{i=t+1}^{t+\tau} r_{i}^{2}$ with $\tau=22$

For example, the first sample point of realized volatility is computed as a sample average of the squared REIT returns from observation 2 to observation 23; the second sample point of realized volatility uses data from observation 3 to observation 24 etc. The historical volatility is constructed in a similar fashion using expression $H V_{t-\tau, \tau}=\frac{1}{\tau} \sum_{i=0}^{\tau-1} r_{t-i}^{2}$.

As a preliminary step to forecast REIT volatility, we need to determine $\mathrm{p}$ and $\mathrm{q}$ in the $\operatorname{GARCH}(p, q), \operatorname{EGARCH}(p, q), \operatorname{FIGARCH}(\mathrm{p}, \mathrm{q}), \operatorname{FIEGARCH}(\mathrm{p}, \mathrm{q})$, and $\operatorname{ARFIMA}(\mathrm{p}, \mathrm{d}, \mathrm{q})$ models. To this end, we experiment with different orders of $\mathrm{p}$ and $\mathrm{q}$ for each model using the full data sample (01/05/1999-04/30/2008). The estimation results are presented in Table 2 and 3. ${ }^{3}$ As 
shown in the tables, there are only slight differences in the values of likelihood function. Therefore, the need for choosing the most parsimonious model leads us to pick $\operatorname{GARCH}(1,1)$, EGARCH(1,1), FIGARCH(1,1), FIEGARCH(1,1) and ARFIMA $(1, \mathrm{~d}, 1)$ to perform forecasting. In practice, these parsimonious models have been found to be adequate in many applications. For example, Bollersev (1986) reported that $\operatorname{GARCH}(1,1)$ is an appropriate model to characterize the volatility behavior for the general U.S. stock market. In the REIT literature, Stevenson (2002), Cotter and Stevenson (2006), Jirasakuldech et al. (2009) showed that $\operatorname{GARCH}(1,1)$ is adequate to model REIT volatility. Cotter and Stevenson (2008) also used $\operatorname{FIGARCH}(1,1)$ and FIEGARCH $(1,1)$ to model the persistence in REIT volatility.

Once the appropriate orders for the models are determined, we need to choose a period for estimating the parameters and a period for predicting volatility. In this paper, we estimate the models using a fixed window size of 2100 observations. The estimation period is then rolled forward by adding one new day and dropping the most distant day. In this way, the sample size used in estimating the models stays at a fixed length and the forecasts do not overlap. For instance, to produce the first 1-day ahead forecast, the first 2100 observations $(01 / 05 / 1999$ to 04/30/2007) of the data sample is used. By doing so, the first 1-day ahead forecast is obtained for 05/01/2007. As the window is rolled over, the models are re-estimated and sequential 1-day ahead forecasts are made. At the end, we generate a total of 250 1-day ahead forecasts ranging from 05/01/2007 to 04/11/2008. ${ }^{4}$ Forecasts for longer horizons (5-, 10-, 15-, 20-, and 25-day) are produced in a similar fashion. ${ }^{5}$ 
The focus of the paper is the evaluation of forecasts from the models. Table 4 reports the evaluation results based on the full sample. Six forecast horizons (1-, 5-, 10-, 15-, 20-, and 25day) are tried. We first look at Panel A where realized volatility (RV) is used as the proxy for the true volatility. By defining the best forecast as having the minimum RMSE and MAE statistics, we find that among all models, ARFIMA model provides the best forecasts for REIT volatility over all forecast horizons and for both evaluation criteria. FIGARCH ranks second except at the 1-day horizon when it loses to SV. SV ranks third for all longer horizons. Following SV is the fourth-ranked GARCH which is our benchmark model. This leaves the asymmetric models (EGRACH \& FIEGARCH) to be the worst performers. The same pattern of models' ranking holds in Panel B where historical volatility (HV) is used as the proxy for the true volatility. As shown there, the dominance of long memory models is well observed except for the 1-day forecast when SV barely beats FIGARCH but not ARFIMA.

Interested readers may notice that our data sample spans from 1999 to 2008 . As discussed in the data section, this is a long period during which REIT volatility has experienced dramatic changes. As such, a question may arise: how the long memory models fare if we use a small data sample and consequently forecast for a different period ${ }^{6}$ To answer such a question, we first need to define the small sample. For this purpose, we resort to structural breaks. It is well known that structural breaks may take place in the REIT market. A number of studies have been devoted to the examination of occurrence of structural breaks in the REIT sector. See, for example, Chui et al. (2003), Ewing and Payne (2005), Jirasakuldech et al. (2009), Kim et al. (2007), and Okunev et al. (2000). If structural breaks did occur, we could divide the full sample into several 
subsamples based on the estimated break dates. By doing so, we can investigate how the long memory models fare in the presumably small subsamples.

To explore the occurrence of structural breaks in REIT volatility, we adopt the procedure proposed by Bai \& Perron (1998). This procedure is designed to detect and locate multiple breaks points with unknown break dates for time series models. As shown in Bai \& Perron (1998), their procedure is capable of producing consistent estimates of the break dates and can successively estimate each break point. This is a distinctive advantage over other methods (e.g. Liu et al. 1997). Empirical applications of the procedure (e.g. Bai and Perron, 2003 and Zeileis et al. 2007) have met with considerable success. Thanks to Zeileis et al. (2007), the procedure can now be easily implemented in R. Here we apply the procedure to the series of realized volatility (RV) which by construction proxies the true volatility $\left(\sigma^{2}\right)$. The results indicate two break points: 6/7/2002 and 5/11/2006. ${ }^{7}$ Generally speaking, the two break points correspond approximately to some well known events that cause volatile market conditions: the technology bubbles that got started during 2002 and then caused great turbulence in the equity market, and the onset of the ongoing subprime mortgage crisis. Based on the two break points, we divide the full sample (1/5/1999-4/30/2008) into three subsamples: subsample I (1/5/1999-6/7/2002), subsample II (6/8/2002-5/11/2006), and subsample III (5/12/2006-4/30/2008). We then forecast REIT volatility based on the three subsamples. Except for a smaller size of the rolling window the forecasting methodology for each subsample is similar to the one used for the full sample. The forecasting results based on the three subsamples are presented in Table 5-7. ${ }^{8}$ As can be seen there, barring the 1-day forecast from subsample I long memory models always produce the best forecasts for REIT volatility. This is consistent with our findings from the full sample. So 
generally speaking, our paper suggests that the long memory models outperform their short memory counterparts in the forecasting of REIT volatility.

The reason for the superiority of long memory models in predicting REIT volatility can be attributed to their ability to approximate the true data generating process. As Poon (2005) pointed out, the success or failure of volatility models depends on the characteristics of empirical data that they try to capture and predict. In other words, the models which best describe the true data generating process of REIT volatility should produce the most accurate forecasts. Given the strong evidence of long memory found for REIT volatility here and in Cotter and Stevenson (2008), we believe that long memory is a genuine property of REIT volatility. This helps to explain the above findings. However, it is worth noting that when the forecast horizon is short (i.e.1-day) long memory models do not necessarily generate better forecasts than their short memory counterparts. This can be seen in Table $4 \& 5$. The reason is that the strength of long memory models lies in its ability to capture long term dependence in volatility and such a strength may not factor into short-term forecasts. And yet we are not the only one to report such a finding. For instance, Zumbach(2004) generates only 1-day ahead volatility forecasts for the USD/CHF exchange rates and finds no difference among the performance of GARCH and FIGRACH models.

The findings of this study have important implications for financial practices because volatility is a critical input to many investment decisions. First, it helps to improve portfolio diversifications. For many portfolio managers, they have certain levels of risk which they can bear. Good forecasts of the volatility of asset returns over the investment holding period are key to assessing investment risks. The longer the holding period, the more benefits of portfolio allocations may 
receive from using long memory models to forecast REIT volatility. The assessment of investment risks becomes more relevant considering the recent turbulence in the REIT market. As mentioned earlier, REITs have traditionally been considered one of the less volatile investment vehicles. Their income-producing and diversification attributes have added to their popularity in long term investments such as retirement plans, in part serving as a dampener for the total portfolio's level of volatility. However, the recent increase of REITs volatility could lessen their appeal in this regard. Those long-term investors that have traditionally invested in the REIT sector now seek to reevaluate the weight of REITs in their portfolios. One important factor affecting their decision making is precise forecasts of REIT volatility, which is the subject of this study.

In addition to the portfolio diversification, our findings are also beneficial to the implementation of derivative pricing and hedging. Volatility is the most important variable in derivative pricing (Poon and Granger, 2003). For example, the well known Black-Scholes formula indicate that the pricing of a U.S. call option is a function of volatility. To price an option, we need to predict the volatility of the underlying asset from now until the option expires. The long memory models better fit this need than their short-memory counterparts. Actually, some attempts have been made to incorporate volatility long memory into derivative pricing for the stock market (e.g. Bollerslev and Mikkelsen, 1996 \& 1999). Their analyses suggest that the average pricing errors from long memory models are less than those from short memory models, especially over moderate to long maturity times. The incorporation of long memory into the pricing of REITbased derivatives has become more important because, as we mentioned earlier, a significant number of REIT-based derivatives have hit the market in the last decade. Since hedging is the 
most basic use of derivatives, it is natural to take account of volatility long memory in the estimation of optimal hedging ratios. A report of NAREIT-Features (May/June 2007) delineates some interesting cases in which the REIT-based derivatives can be used to manage risks. For instance, pension and hedge funds can use the derivatives to hedge either property type or geographic risk, or to achieve for portfolio diversification that's easier and less costly than direct

real estate investment. Lenders, such as banks and insurance firms can use the derivatives to guard against downside risk on their loan portfolios. Finally, our findings could also lead to improved decision making for financial risk management. Since the establishment of the Basel Committee and Banking Supervision (1996), financial risk management has been assuming increasing importance. Financial institutions like banks are required to put aside a sufficient amount of capital as a cushion against adverse market movements. The amount of capital is usually measured by Value-at-Risk (VaR) which is defined as the maximal loss of a financial position during a given time period for a given probability. Computations of VaR require volatility forecasts. As such, accurate volatility forecasting just becomes a compulsory riskmanagement excise for many financial institutions.

\section{Conclusions}

As a consequence of significant growth in market capitalization and trading volume, REIT has recently become a more important asset class that warrants greater attention from practitioners, policy makers, and academics. In contrast to the extensive literature on the return behavior of REIT, only a few papers examine REIT volatility and even worse none of them have yet attempted to identify the best model to forecast REIT volatility. This study attempts to fill the 
gap. With the increasing REIT volatility in recent years, the need for precise forecasts of REIT volatility is expected to be growing as many investors seek to reevaluate the REITs' place in their investment plans.

In this study, using a large sample of daily data from FTSE we compare the performance of six alternative models for forecasting REIT volatility. The competing models include both shortmemory models such as GARCH, EGARCH and SV models and long-memory models such as FIGARCH, FIEGARCH and ARFIMA models. Overall our findings suggest that the longmemory models (ARFIMA \& FIGARCH) dominate over their short-memory counterparts (GARCH \& SV) in forecasting REIT volatility over a variety of forecast horizons and the asymmetric models (EGARCH \& FIEGARCH) are not very useful for predicting REIT volatility. The same findings hold when we conduct the forecasting based on small subsamples defined by statistically justified break points in the proxies of REIT volatility process. Based on these findings, we conclude that the long-memory models should be used not only to model REIT volatility, as argued by Cotter and Stevenson (2008), but also to forecast volatility. Since volatility forecasts are important inputs to portfolio selections, derivative pricing and hedging, and financial risk managements, our findings have important implications for these financial activities. 


\section{Notes:}

1. For instance, in February 2007 the Chicago Board of Trade launched its new futures contract based on the Dow Jones U.S. Real Estate Index (DJUSRE). As of March 31, 2007, the DJUSRE Index included 91 constituents, of which 85 were REITs. The DJUSRE Index futures contract trades electronically six days a week, and has a value equal to 100 multiplied by the value of the DJUSRE.

2. The distribution of REIT returns is estimated using the Kernel density estimation method.

3. In this paper, we use the Ox software to estimate the models and perform the forecasting.

4. The forecast period ends on $04 / 11 / 2008$. Due to the construction method, the last RV that can be generated is for $04 / 11 / 2008$, which is 22 days prior to $04 / 30 / 2008$, the ending date of our data sample.

5. There are only 2465 -day ahead forecasts $(05 / 04 / 2007-04 / 11 / 2008)$ because the first forecast we can obtain is for 05/04/2007. It occurs when the rolling window is fixed at the first 2100 observations (01/05/1999 to 04/30/2007). In a similar reasoning, for 10-, 15-, 20-, and 25-day horizons, we generate 241, 236, 231, and 226 forecasts, respectively.

6. We are indebted to an anonymous reviewer for bringing attention to this point. 
7. Applying this procedure to the historical volatility (HV) also yields two break points6/7/2002 and 5/11/2006. Compared with the two break points generated from realized volatility $(\mathrm{RV})$, the first one is very close and the second one is actually the same.

8. Using the three subsamples defined by the two break points generated from the historical volatility (HV), we obtain very similar forecasting results. To conserve space, they are not shown here but are available upon request. 


\section{References}

Anderson, T. and B. Sorensen. (1996). GMM Estimation of a Stochastic Volatility Model: A Monte Carlo Study. Journal of Business and Economics Statistics, 14, 329-52.

Anderson, T. G. and T. Bollerslev. (1997a). Heterogeneous Information Arrivals and Return Volatility Dynamics: Uncovering the Long-run in High Frequency Returns. Journal of Finance, $52,975-1005$.

Andersen, T. G. and T. Bollerslev. (1997b). Intraday Periodicity and Volatility Persistence in Financial Markets. Journal of Empirical Finance, 4, 115-58.

Bai, J. and P. Perron. (1998). Estimating and Testing Linear Models with Multiple Structural Changes. Econometrica, 66, 47-78.

Bai, J. and P. Perron. (2003). Computation and Analysis of Multiple Structural Change Models. Journal of Applied Econometrics, 18, 1-22.

Baillie, R. T., T. Bollerslev, and H.O. Mikkelsen. (1996). Fractionally Integrated Generalized Conditional Heteroskedasticity. Journal of Econometrics, 74, 3-30.

Barkham, R. and D. Geltner. (1995). Price discovery in American and British property markets. Real Estate Economics, 23, 21-44. 
Bollerslev, Tim. (1986). Generalized autoregressive conditional heteroskedasticity, Journal of Econometrics. 31,307-327.

Bollerslev, Tim and Mikkelsen, H.O. (1996). Modeling and pricing long memory in stock market volatility. Journal of Econometrics, 73,151-184.

Bollerslev, Tim and Mikkelsen, H.O. (1999). Long-Term Equity Anticipation Securities and Stock Market Volatility Dynamics. Journal of Econometrics, 92, 75-99.

Bredin, D., G. O'Reilly, and S. Stevenson. (2007). Monetary shocks and REIT returns. Journal of Real Estate Finance and Economics. 35, 315-31.

Brockwell, P.J. and R.A. Davis. (1991). Time Series: Theory and Methods. Spring-Verlag: New York.

Chandrashekaran, V. (1999). Time-series properties and diversification benefits of REIT returns. Journal of Real Estate Research, 17, 91-112.

Chui, A.C.W., S. Titman, and K.C.J. Wei. (2003). Intra-industry Momentum: the Case of REITs. Journal of Financial Markets, 6, 363-387.

Cotter, J. and S. Stevenson. (2006). Multivariate modeling of daily REIT volatility. Journal of 
Real Estate Finance and Economics, 32, 305-25.

Cotter, J. and S. Stevenson. (2008). Modeling long memory in REITs. Real Estate Economics,36, $533-54$.

Danielsson, J. (1994). Stochastic Volatility in Asset Prices: Estimation with Simulated Maximum Likelihood. Journal of Econometrics, 64, 375-400.

Devaney, M. (2001). Time-varying risk premia for real estate investment trusts: a GARCH-M model. Quarterly Review of Economics and Finance, 41, 335-46.

Ding, Z., C.W.J. Granger, and R.F. Engle. (1993). A Long Memory Property of Stock Returns. Journal of Empirical Finance, 1, 83-106.

Evans, T. and D. G. McMillan. (2007). Volatility Forecasts: the Role of Asymmetric and Longmemory Dynamics and Regional Evidence. Applied Financial Economics, 17, 1421-30.

Ewing, B.T., and J.E.Payne. (2005). The Response of Real Estate Investment Trust Returns to Macroeconomic Shocks. Journal of Business Research ,58, 293-300.

Ghysels, E., A. Harvey, and E. Renault. (1996). Stochastic Volatility. In Handbook of Statistics. Vol. 14: Statistical Methods in Finance, Maddala, G.S. (ed.) North-Holland, Amsterdam, pp. $119-91$. 
Gospodinov, N. , A. Gavala, and D. Jiang. (2006). Forecasting Volatility, Journal of Forecasting, $25,381-400$.

Granger, C. and R. Joyeux. (1980). An Introduction to Long Memory Time Series Models and Fractional Differencing. Journal of Time Series Analysis, 1, 15-39.

Horng, Y. S. and P. H. Wei. (1999). An Empirical Study of Derivatives Use in the REIT Industry. Real Estate Economics, 27, 561-86.

Hosking, J. (1981). Fractional Differencing. Biometrika, 68, 165-76.

Jirasakuldech, B., R.D. Campbell, and R. Emekter. (2009). Conditional Volatility of Equity Real Estate Investment Trust Returns: A Pre- and Post-1993 Comparison. Journal of Real Estate Finance and Economics, forthcoming.

Kim, J.W., D.J. Leatham, and D.A. Bessler. (2007). REITs' Dynamics under Structural Change with Unknown Break Points. Journal of Housing Economics, 16, 37-58.

Kim, Sangjoon, Neil Shephard, and Siddhartha Chib.(1998). Stochastic volatility: Likelihood Inference and Comparison with ARCH Models, Review of Economic Studies, 65, 361-93.

Lamoureux, C.G. and W.D. Lastrapes. (1990). Heteroskedasticity in Stock Return Data: Volume 
versus GARCH Effects. Journal of Finance, 45, 221-29.

Li, Y. and K. Wang. (1995). The predictability of REIT returns and market segmentation. Journal of Real Estate Research, 10, 471-82.

Ling, D. and A. Naranjo. (1999). The integration of commercial real estate markets and stock markets. Real Estate Economics, 27, 483-515.

Liu, C. H., D.J. Hartzell, W. Greig and T. Grissom. (1990). The integration of the real estate market and the stock market: some preliminary evidence. Journal of Real Estate Finance and Economics, 3, 261-82.

Liu, C. H. and J. Mei. (1992). The predictability of returns on equity REITs and their comovement with other assets. Journal of Real Estate Finance and Economics, 5, 401-18.

Liu, J., S. Wu, and J.V.Zidek. (1997). On Segmented Multivariate Regressions. Statistica Sinica, 7, 497-525.

Lobato, I.N. and N.E. Savin. (1998). Real and Spurious Long-Memory Properties of StockMarket Data. Journal of Business \& Economic Statistics, 16, 261-68.

Mei, J. and A. Lee. (1994). Is there a real estate risk premium? Journal of Real Estate Finance and Economics, 9, 113-26. 
Myer, F.C.N. and J. R. Webb. (1994). Statistical properties of returns: financial assets versus commercial real estate. Journal of Real Estate Finance and Economics, 8, 267-82.

Nelson,D.B. (1989). Commentary: Price Volatility, International Market Links, and Their Implications for Regulatory Policies. Journal of Financial Services Research, 3, 113-48.

Nelson,D.B. (1991). Conditional Heteroskedasticity in Asset Returns: A New Approach, Econometrica, 59, 347-370.

Okunev, J., P. Wilson, and R. Zurbruegg. (2000). The Causal Relationship between Real Estate and Stock Markets. Journal of Real Estate Finance and Economics ,21,251-261.

Poon, S. H. and Clive W. J. Granger. (2003). Forecasting Volatility in Financial Markets: A Review. Journal of Economic Literature, 41, 478-539.

Poon, S. H. (2005). Forecasting Volatility in Financial Markets: A Practical Guide. John Wiley $\&$ Sons.

Ruiz, E. (1994). Quasi-maximum Likelihood Estimation of Stochastic Volatility Models. Journal of Econometrics, 63, 289-306.

Seiler, M.J., J.R.Webb and F.C.N. Myer. (1999). Are EREITs real estate? Journal of Real Estate 
Portfolio Management, 5, 171-82.

Shephard, N. (1996). Statistical Aspects of ARCH and Stochastic Volatility Models. In Time Series Models in Econometrics, Finance and Other Fields, D.R. Cox, D.V. Hinkley, and O.E. Bandorff-Nielsen (ed.) Chapman \& Hall, London, pp. 1-67.

So, M.K.P., K. Lam, and W.K. Li. (1999). Forecasting Exchange Rate Volatility Using Autoregressive Random Variance Model. Applied Financial Economics, 9, 583-91.

Sowell, F.B. (1992). Maximum Likelihood Estimation of Stationary Univariate Fractionally Integrated Time Series Models. Journal of Econometrics, 53, 165-188.

Stevenson, S. (2002). An examination of volatility spillovers in REIT returns. Journal of Real Estate Portfolio Management, 8, 229-38.

Taylor, S.J. (1982). Financial Returns Modeled by the Product of Two Stochastic Processes- A Study of Daily Sugar Prices, in Time Series Analysis: Theory and Practice 1, (Ed.) O. D. Anderson, North Holland, Amsterdam, pp. 203-26.

Taylor, S.J. (1986). Modeling Financial Time Series. Wiley, Chichester.

Winniford, M. (2003). Real Estate Investment Trusts and seasonal volatility: a periodic GARCH model, working paper, Duke University. 
Yu, J. (2002). Forecasting Volatility in the New Zealand Stock Market. Applied Financial Economics, 12, 193-202.

Zeileis,A., A.Shah, and I.Patnaik. (2007). Exchange Rate Regime Analysis Using Structural Change Methods. Working Paper, Department of Statistics and Mathematics, Wien, Wirtschaftsuniv.

Zumbach, Gilles. (2004). Volatility processes and volatility forecast with long memory. Quantitative Finance, 4, 70-86. 
Table 1 Descriptive statistics of daily REIT returns

\begin{tabular}{lr}
\hline Mean & 0.00049 \\
Median & 0.00051 \\
Variance & 1.07754 \\
Standard Deviation & 1.03805 \\
Skewness & 0.02270 \\
Kurtosis & 5.33180 \\
Maximum & 0.08058 \\
Minimum & -0.05611 \\
Range & 0.13669 \\
\hline
\end{tabular}

Notes: This table reports the summary statistics for daily REIT returns from 01/05/1999 to 04/30/2008. The skewness and kurtosis statistics have a value of zero for a normal distribution

Table 2 Experimentations with different orders of $\mathrm{p}$ and $\mathrm{q}$ for the GARCH-related Models

\begin{tabular}{lccccccccc}
\hline Models & $\alpha_{0}$ & $\alpha_{1}$ & $\alpha_{2}$ & $\beta_{1}$ & $\beta_{2}$ & $\lambda_{1}$ & $\lambda_{2}$ & $\hat{d}$ & Likelihood \\
\hline $\operatorname{GARCH}(1,1)$ & 0.000002 & 0.136 & & 0.850 & & & & 7887.1 \\
& $(0.000001)$ & $(0.019)$ & & $(0.019)$ & & & \\
$\operatorname{GARCH}(2,1)$ & 0.000002 & 0.183 & -0.067 & 0.872 & & & 7888.8 \\
& $(0.000001)$ & $(0.035)$ & $(0.039)$ & $(0.021)$ & & & \\
$\operatorname{GARCH}(1,2)$ & 0.000003 & 0.201 & & 0.214 & 0.563 & & 7891.0 \\
& $(0.000001)$ & $(0.027)$ & & $(0.101)$ & $(0.096)$ & & \\
$\operatorname{GARCH}(2,2)$ & 0.000004 & 0.171 & 0.077 & -0.055 & 0.781 & & & \\
& & & & & & & & \\
\end{tabular}




\begin{tabular}{|c|c|c|c|c|c|c|c|c|c|}
\hline & $(0.000001)$ & $(0.023)$ & $(0.025)$ & $(0.041)$ & $(0.034)$ & & & & \\
\hline $\operatorname{EGARCH}(1,1)$ & $\begin{array}{r}9.590 \\
(0.184)\end{array}$ & $\begin{array}{l}-0.036 \\
(0.134)\end{array}$ & & $\begin{array}{c}0.921 \\
(0.008)\end{array}$ & & $\begin{array}{l}-0.063 \\
(0.022)\end{array}$ & $\begin{array}{c}0.371 \\
(0.501)\end{array}$ & & 7830.6 \\
\hline $\operatorname{EGARCH}(2,1)$ & $\begin{array}{c}9.290 \\
(0.167)\end{array}$ & $\begin{array}{l}-0.325 \\
(0.149)\end{array}$ & $\begin{array}{c}0.360 \\
(0.140)\end{array}$ & $\begin{array}{l}0.913 \\
(0.10)\end{array}$ & & $\begin{array}{l}-0.056 \\
(0.022)\end{array}$ & $\begin{array}{c}0.374 \\
(0.050)\end{array}$ & & 7829.1 \\
\hline $\operatorname{EGARCH}(1,2)$ & $\begin{array}{c}7.601 \\
(0.194)\end{array}$ & $\begin{array}{l}-0.742 \\
(0.135)\end{array}$ & & $\begin{array}{l}-0.004 \\
(0.060)\end{array}$ & $\begin{array}{c}0.838 \\
(0.054)\end{array}$ & $\begin{array}{l}-0.062 \\
(0.022)\end{array}$ & $\begin{array}{c}0.392 \\
(0.040)\end{array}$ & & 7831.9 \\
\hline $\operatorname{EGARCH}(2,2)$ & $\begin{array}{c}9.182 \\
(0.289)\end{array}$ & $\begin{array}{l}-0.285 \\
(0.411)\end{array}$ & $\begin{array}{c}0.354 \\
(0.145)\end{array}$ & $\begin{array}{l}0.874 \\
(0.361)\end{array}$ & $\begin{array}{l}0.035 \\
(0.331)\end{array}$ & $\begin{array}{l}-0.056 \\
(0.022)\end{array}$ & $\begin{array}{c}0.374 \\
(0.050)\end{array}$ & & 7829.1 \\
\hline FIGARCH $(1,1)$ & $\begin{array}{c}0.000002 \\
(0.000001)\end{array}$ & $\begin{array}{c}0.290 \\
(0.071)\end{array}$ & & $\begin{array}{c}0.624 \\
(0.089)\end{array}$ & & & & $\begin{array}{r}0.504 \\
(0.093)\end{array}$ & 7894.1 \\
\hline FIGARCH $(2,1)$ & $\begin{array}{c}0.000004 \\
(0.000002)\end{array}$ & $\begin{array}{c}0.062 \\
(0.220)\end{array}$ & $\begin{array}{l}-0.103 \\
(0.058)\end{array}$ & $\begin{array}{c}0.331 \\
(0.270)\end{array}$ & & & & $\begin{array}{r}0.443 \\
(0.080)\end{array}$ & 7895.3 \\
\hline FIGARCH(1,2) & $\begin{array}{c}0.000005 \\
(0.000002)\end{array}$ & $\begin{array}{l}-0.352 \\
(0.299)\end{array}$ & & $\begin{array}{l}-0.067 \\
(0.316)\end{array}$ & $\begin{array}{c}0.226 \\
(0.850)\end{array}$ & & & $\begin{array}{l}0.459 \\
(0.078)\end{array}$ & 7896.0 \\
\hline FIGARCH(2,2) & $\begin{array}{c}0.000005 \\
(0.000002)\end{array}$ & $\begin{array}{l}-0.657 \\
(0.075)\end{array}$ & $\begin{array}{c}0.206 \\
(0.073)\end{array}$ & $\begin{array}{l}-0.328 \\
(0.096)\end{array}$ & $\begin{array}{c}0.546 \\
(0.091)\end{array}$ & & & $\begin{array}{c}0.503 \\
(0.091)\end{array}$ & 7897.6 \\
\hline FIEGARCH $(1,1)$ & $\begin{array}{c}5.837 \\
(0.157)\end{array}$ & $\begin{array}{l}-0.026 \\
(0.136)\end{array}$ & & $\begin{array}{c}0.931 \\
(0.009)\end{array}$ & & $\begin{array}{l}-0.078 \\
(0.023)\end{array}$ & $\begin{array}{c}0.352 \\
(0.049)\end{array}$ & $\begin{array}{l}-0.048 \\
(0.011)\end{array}$ & 7850.6 \\
\hline FIEGARCH $(2,1)$ & $\begin{array}{c}5.492 \\
(0.128)\end{array}$ & $\begin{array}{l}-0.303 \\
(0.150)\end{array}$ & $\begin{array}{c}0.352 \\
(0.142)\end{array}$ & $\begin{array}{c}0.922 \\
(0.010)\end{array}$ & & $\begin{array}{l}-0.075 \\
(0.021)\end{array}$ & $\begin{array}{c}0.355 \\
(0.048)\end{array}$ & $\begin{array}{l}-0.048 \\
(0.008)\end{array}$ & 7848.5 \\
\hline FIEGARCH $(1,2)$ & $\begin{array}{l}4.418 \\
(0.130)\end{array}$ & $\begin{array}{l}0.772 \\
(0.138)\end{array}$ & & $\begin{array}{c}0.013 \\
(0.065)\end{array}$ & $\begin{array}{c}0.864 \\
(0.060)\end{array}$ & $\begin{array}{l}-0.080 \\
(0.021)\end{array}$ & $\begin{array}{c}0.376 \\
(0.039)\end{array}$ & $\begin{array}{l}-0.053 \\
(0.008)\end{array}$ & 7858.4 \\
\hline FIEGARCH $(2,2)$ & $\begin{array}{l}4.932 \\
(0.148)\end{array}$ & $\begin{array}{c}0.085 \\
(0.411)\end{array}$ & $\begin{array}{c}0.316 \\
(0.168)\end{array}$ & $\begin{array}{c}0.574 \\
(0.326)\end{array}$ & $\begin{array}{c}0.322 \\
(0.303)\end{array}$ & $\begin{array}{l}-0.074 \\
(0.021)\end{array}$ & $\begin{array}{c}0.352 \\
(0.048)\end{array}$ & $\begin{array}{l}-0.049 \\
(0.008)\end{array}$ & 7849.1 \\
\hline
\end{tabular}

Notes: This table reports the estimation results obtained by trying different orders of $\mathrm{p}$ an $\mathrm{q}$ for various GARCH-related models using the full data sample (01/05/1999-04/30/2008). The numbers in parentheses are standard errors of the estimated coefficients.

Table 3 Experimentations with different orders of $\mathrm{p}$ and $\mathrm{q}$ for the ARFIMA Model

\begin{tabular}{|c|c|c|c|c|c|c|}
\hline Models & $\phi_{1}$ & $\phi_{2}$ & $\theta_{1}$ & $\theta_{2}$ & $\hat{d}$ & Likelihood \\
\hline $\operatorname{ARFIMA}(1, \mathrm{~d}, 1)$ & $\begin{array}{r}0.254 \\
(0.047)\end{array}$ & & $\begin{array}{r}-0.611 \\
(0.058)\end{array}$ & & $\begin{array}{l}0.409 \\
(0.045)\end{array}$ & 16054.7 \\
\hline $\operatorname{ARFIMA}(2, \mathrm{~d}, 1)$ & $\begin{array}{c}-0.081 \\
(0.193)\end{array}$ & $\begin{array}{l}-0.129 \\
(0.049)\end{array}$ & $\begin{array}{l}-0.200 \\
(0.223)\end{array}$ & & $\begin{array}{l}0.340 \\
(0.039)\end{array}$ & 16057.1 \\
\hline
\end{tabular}




\begin{tabular}{|c|c|c|c|c|c|c|}
\hline $\operatorname{ARFIMA}(1, \mathrm{~d}, 2)$ & $\begin{array}{r}-0.379 \\
(0.185)\end{array}$ & & $\begin{array}{c}0.067 \\
(0.198)\end{array}$ & $\begin{array}{l}-0.237 \\
(0.057)\end{array}$ & $\begin{array}{c}0.370 \\
(0.040)\end{array}$ & 16058.6 \\
\hline $\operatorname{ARFIMA}(2, \mathrm{~d}, 2)$ & $\begin{array}{r}-0.703 \\
(0.059)\end{array}$ & $\begin{array}{l}0.179 \\
(0.056)\end{array}$ & $\begin{array}{l}0.367 \\
(0.071)\end{array}$ & $\begin{array}{l}-0.533 \\
(0.071)\end{array}$ & $\begin{array}{l}0.370 \\
(0.040)\end{array}$ & 16061.5 \\
\hline
\end{tabular}

Notes: This table reports the estimation results obtained by trying different orders of $\mathrm{p}$ an $\mathrm{q}$ for ARFIMA model using the full data sample (01/05/1999-04/30/2008). The numbers in parentheses are standard errors of the estimated coefficients.

Table 4 Evaluations of REIT volatility forecasts based on the full sample

\begin{tabular}{|c|c|c|c|c|c|c|}
\hline \multirow[b]{2}{*}{ Models } & \multirow[b]{2}{*}{ 1-day } & \multicolumn{4}{|c|}{ Forecast Horizons } & \multirow[b]{2}{*}{ 25-day } \\
\hline & & 5-day & 10-day & 15-day & 20-day & \\
\hline \multicolumn{7}{|c|}{ Panel A: realized volatility ( $R V$ ) as proxy } \\
\hline \multicolumn{7}{|c|}{ I. RMSE as the evaluation criterion } \\
\hline$\overline{\operatorname{GARCH}(1,1)}$ & $0.0065(4)$ & $0.0073(4)$ & $0.0084(4)$ & $0.0095(4)$ & $0.0106(4)$ & $0.0117(4)$ \\
\hline $\operatorname{EGARCH}(1,1)$ & $0.0079(6)$ & $0.1167(5)$ & $0.4431(5)$ & $0.7235(5)$ & $0.9372(5)$ & $0.9384(5)$ \\
\hline SV & $0.0058(2)$ & $0.0062(3)$ & $0.0068(3)$ & $0.0074(3)$ & $0.0080(3)$ & $0.0086(3)$ \\
\hline $\operatorname{FIGARCH}(1,1)$ & $0.0061(3)$ & $0.0061(2)$ & $0.0066(2)$ & $0.0070(2)$ & $0.0073(2)$ & $0.0078(2)$ \\
\hline $\operatorname{FIEGARCH}(1,1)$ & $0.0075(5)$ & $0.1631(6)$ & $0.7936(6)$ & $1.5575(6)$ & $2.0645(6)$ & $2.2901(6)$ \\
\hline $\operatorname{ARFIMA}(1, \mathrm{~d}, 1)$ & $0.0057(1)$ & $0.0059(1)$ & $0.0061(1)$ & $0.0064(1)$ & $0.0067(1)$ & $0.0070(1)$ \\
\hline \multicolumn{7}{|c|}{ II. MAE as the evaluation criterion } \\
\hline $\operatorname{GARCH}(1,1)$ & $0.0054(4)$ & $0.0061(4)$ & $0.0071(4)$ & $0.0084(4)$ & $0.0096(4)$ & $0.0109(4)$ \\
\hline $\operatorname{EGARCH}(1,1)$ & $0.0064(6)$ & $0.1156(5)$ & $0.4426(5)$ & $0.7233(5)$ & $0.9372(5)$ & $0.9384(5)$ \\
\hline SV & $0.0048(2)$ & $0.0052(3)$ & $0.0057(3)$ & $0.0064(3)$ & $0.0070(3)$ & $0.0076(3)$ \\
\hline FIGARCH $(1,1)$ & $0.0049(3)$ & $0.0051(2)$ & $0.0055(2)$ & $0.0059(2)$ & $0.0064(2)$ & $0.0067(2)$ \\
\hline $\operatorname{FIEGARCH}(1,1)$ & $0.0060(5)$ & $0.1616(6)$ & $0.7926(6)$ & $1.5571(6)$ & $2.0643(6)$ & $2.2898(6)$ \\
\hline $\operatorname{ARFIMA}(1, \mathrm{~d}, 1)$ & $0.0047(1)$ & $0.0050(1)$ & $0.0051(1)$ & $0.0054(1)$ & $0.0057(1)$ & $0.0060(1)$ \\
\hline \multicolumn{7}{|c|}{ Panel B: historical volatility (HV) as proxy } \\
\hline \multicolumn{7}{|c|}{ I. RMSE as the evaluation criterion } \\
\hline $\operatorname{GARCH}(1,1)$ & $0.0039(4)$ & $0.0049(4)$ & $0.0064(4)$ & $0.0083(4)$ & $0.0101(4)$ & $0.0116(4)$ \\
\hline $\operatorname{EGARCH}(1,1)$ & $0.0072(6)$ & $0.1171(5)$ & $0.4436(5)$ & $0.7234(5)$ & $0.9375(5)$ & $0.9386(5)$ \\
\hline SV & $0.0032(2)$ & $0.0039(3)$ & $0.0051(3)$ & $0.0063(3)$ & $0.0074(3)$ & $0.0083(3)$ \\
\hline $\operatorname{FIGARCH}(1,1)$ & $0.0038(3)$ & $0.0038(2)$ & $0.0049(2)$ & $0.0059(2)$ & $0.0067(2)$ & $0.0074(2)$ \\
\hline FIEGARCH $(1,1)$ & $0.0068(5)$ & $0.1635(6)$ & $0.7941(6)$ & $1.5579(6)$ & $2.0649(6)$ & $2.2904(6)$ \\
\hline $\operatorname{ARFIMA}(1, \mathrm{~d}, 1)$ & $0.0029(1)$ & $0.0033(1)$ & $0.0041(1)$ & $0.0050(1)$ & $0.0059(1)$ & $0.0065(1)$ \\
\hline
\end{tabular}


II. MAE as the evaluation criterion

$\begin{array}{lllllll}\text { GARCH }(1,1) & 0.0031(4) & 0.0041(4) & 0.0059(4) & 0.0076(4) & 0.0092(4) & 0.0106(4) \\ \text { EGARCH(1,1) } & 0.0059(6) & 0.1163(5) & 0.4432(5) & 0.7238(5) & 0.9375(5) & 0.9386(5) \\ \text { SV } & 0.0024(2) & 0.0032(3) & 0.0044(3) & 0.0055(3) & 0.0065(3) & 0.0073(3) \\ \text { FIGARCH }(1,1) & 0.0030(3) & 0.0031(2) & 0.0041(2) & 0.0050(2) & 0.0057(2) & 0.0063(2) \\ \text { FIEGARCH(1,1) } & 0.0055(5) & 0.1623(6) & 0.7931(6) & 1.5575(6) & 2.0646(6) & 2.2901(6) \\ \text { ARFIMA }(1, \mathrm{~d}, 1) & 0.0023(1) & 0.0026(1) & 0.0033(1) & 0.0042(1) & 0.0050(1) & 0.0056(1)\end{array}$

Notes: This table evaluates the performance of different models in the forecasting of REIT volatility based on the full sample (01/05/1999-04/30/2008). The forecast period is 05/01/2007 to 04/11/2008 and a fixed rolling window of 2100 observations is used. RMSE is root mean square error. MAE is mean absolute error. The numbers in parentheses are the relative ranking of each model for the corresponding evaluation criterion.

Table 5 Evaluations of REIT volatility forecasts based on subsample I

\begin{tabular}{lllllll}
\hline & \multicolumn{5}{c}{ Forecast Horizons } \\
Models & 1-day & 5-day & 10-day & 15-day & 20-day & 25-day \\
\hline
\end{tabular}

Panel A: realized volatility $(\mathrm{RV})$ as proxy

I. RMSE as the evaluation criterion

\begin{tabular}{|c|c|c|c|c|c|c|}
\hline $\operatorname{GARCH}(1,1)$ & $0.0052(3)$ & $0.0067(4)$ & $0.0078(4)$ & $0.0081(4)$ & $0.0081(4)$ & $0.0086(4)$ \\
\hline EGARCH $(1,1)$ & $0.3818(5)$ & $0.9976(5)$ & $0.9929(5)$ & $0.9928(5)$ & $0.9927(5)$ & $0.9924(5)$ \\
\hline SV & $0.0049(2)$ & $0.0049(3)$ & $0.0055(3)$ & $0.0059(3)$ & $0.0059(3)$ & $0.0064(3)$ \\
\hline $\operatorname{FIGARCH}(1,1)$ & $0.0234(4)$ & $0.0031(2)$ & $0.0036(2)$ & $0.0037(2)$ & $0.0037(2)$ & $0.0040(2)$ \\
\hline $\operatorname{FIEGARCH}(1,1)$ & $0.5744(6)$ & $1.3289(6)$ & $1.2404(6)$ & $1.2058(6)$ & $1.1835(6)$ & $1.1670(6)$ \\
\hline $\operatorname{ARFIMA}(1, \mathrm{~d}, 1)$ & $0.0034(1)$ & $0.0029(1)$ & $0.0034(1)$ & $0.0036(1)$ & $0.0036(1)$ & $0.0039(1)$ \\
\hline \multicolumn{7}{|c|}{ II. MAE as the evaluation criterion } \\
\hline $\operatorname{GARCH}(1,1)$ & $0.0040(3)$ & $0.0775(4)$ & $0.0838(4)$ & $0.0849(4)$ & $0.0855(4)$ & $0.0875(4)$ \\
\hline EGARCH $(1,1)$ & $0.3817(5)$ & $0.9988(5)$ & $0.9964(5)$ & $0.9964(5)$ & $0.9963(5)$ & $0.9962(5)$ \\
\hline SV & $0.0037(2)$ & $0.0630(3)$ & $0.0656(3)$ & $0.0665(3)$ & $0.0667(3)$ & $0.0692(3)$ \\
\hline $\operatorname{FIGRACH}(1,1)$ & $0.0078(4)$ & $0.0455(2)$ & $0.0469(2)$ & $0.0483(1)$ & $0.0483(2)$ & $0.0506(2)$ \\
\hline FIEGARCH $(1,1)$ & $0.5744(6)$ & $1.1528(6)$ & $1.1137(6)$ & $1.0981(6)$ & $1.0879(6)$ & $1.0803(6)$ \\
\hline $\operatorname{ARFIMA}(1, \mathrm{~d}, 1)$ & $0.0021(1)$ & $0.0432(1)$ & $0.0459(1)$ & $0.0483(1)$ & $0.0478(1)$ & $0.0502(1)$ \\
\hline
\end{tabular}

Panel B: historical volatility (HV) as proxy

I. RMSE as the evaluation criterion

\begin{tabular}{|c|c|c|c|c|c|c|}
\hline $\operatorname{GARCH}(1,1)$ & $0.0035(3)$ & $0.0056(4)$ & $0.0059(4)$ & $0.0060(4)$ & $0.0059(4)$ & $0.0058(4)$ \\
\hline $\operatorname{EGARCH}(1,1)$ & $0.3825(5)$ & $0.9981(5)$ & $0.9941(5)$ & $0.9941(5)$ & $0.9942(5)$ & $0.9943(5)$ \\
\hline SV & $0.0034(2)$ & $0.0038(3)$ & $0.0034(3)$ & $0.0034(3)$ & $0.0033(3)$ & $0.0032(3)$ \\
\hline FIGARCH $(1,1)$ & $0.0234(4)$ & $0.0013(2)$ & $0.0014(2)$ & $0.0014(2)$ & $0.0014(2)$ & $0.0014(2)$ \\
\hline $\operatorname{FIEGARCH}(1,1)$ & $0.5752(6)$ & $1.3295(6)$ & $1.2416(6)$ & $1.2072(6)$ & $1.1850(6)$ & $1.1689(6)$ \\
\hline $\operatorname{ARFIMA}(1, \mathrm{~d}, 1)$ & $0.0012(1)$ & $0.0010(1)$ & $0.0012(1)$ & $0.0013(1)$ & $0.0013(1)$ & $0.0015(1)$ \\
\hline
\end{tabular}


II. MAE as the evaluation criterion

$\begin{array}{lllllll}\text { GARCH }(1,1) & 0.0031(3) & 0.0738(4) & 0.0762(4) & 0.0766(4) & 0.0763(4) & 0.0753(4) \\ \text { EGARCH }(1,1) & 0.3825(5) & 0.9991(5) & 0.9970(5) & 0.9971(5) & 0.9971(5) & 0.9972(5) \\ \text { SV } & 0.0029(2) & 0.0583(3) & 0.0553(3) & 0.0550(3) & 0.0541(3) & 0.0528(3) \\ \text { FIGARCH }(1,1) & 0.0065(4) & 0.0321(2) & 0.0335(2) & 0.0341(2) & 0.0344(2) & 0.0354(2) \\ \text { FIEGARCH(1,1) } & 0.5752(6) & 1.1530(6) & 1.1143(6) & 1.0987(6) & 1.0886(6) & 1.0812(6) \\ \text { ARFIMA }(1, \mathrm{~d}, 1) & 0.0010(1) & 0.0287(1) & 0.0310(1) & 0.0332(1) & 0.0337(1) & 0.0347(1)\end{array}$

Notes: This table evaluates the performance of different models in the forecasting of REIT volatility based on subsample I (01/05/1999-06/07/2002). The forecast period is 06/07/2001 to 06/07/2002 and a fixed rolling window of 612 observations is used. RMSE is root mean square error. MAE is mean absolute error. The numbers in parentheses are the relative ranking of each model for the corresponding evaluation criterion.

Table 6 Evaluations of REIT volatility forecasts based on subsample II

\begin{tabular}{|c|c|c|c|c|c|c|}
\hline \multirow[b]{2}{*}{ Models } & \multicolumn{6}{|c|}{ Forecast Horizons } \\
\hline & 1-day & 5-day & 10-day & 15-day & 20-day & 25-day \\
\hline
\end{tabular}

Panel A: realized volatility $(\mathrm{RV})$ as proxy

I. RMSE as the evaluation criterion

\begin{tabular}{|c|c|c|c|c|c|c|}
\hline $\operatorname{GARCH}(1,1)$ & $0.0030(4)$ & $0.0055(4)$ & $0.0059(4)$ & $0.0069(4)$ & $0.0077(4)$ & $0.0084(4)$ \\
\hline $\operatorname{EGARCH}(1,1)$ & $0.0126(6)$ & $0.2985(6)$ & $0.7440(6)$ & $0.9242(5)$ & $0.9732(5)$ & $0.9852(5)$ \\
\hline SV & $0.0025(3)$ & $0.0044(3)$ & $0.0044(3)$ & $0.0046(3)$ & $0.0049(2)$ & $0.0051(3)$ \\
\hline FIGARCH $(1,1)$ & $0.0018(2)$ & $0.0033(2)$ & $0.0031(2)$ & $0.0029(2)$ & $0.0028(1)$ & $0.0025(2)$ \\
\hline $\operatorname{FIEGARCH}(1,1)$ & $0.0099(5)$ & $0.2674(5)$ & $0.7407(5)$ & $0.9705(6)$ & $1.0395(6)$ & $1.0548(6)$ \\
\hline $\operatorname{ARFIMA}(1, \mathrm{~d}, 1)$ & $0.0014(1)$ & $0.0032(1)$ & $0.0029(1)$ & $0.0027(1)$ & $0.0027(1)$ & $0.0024(1)$ \\
\hline \multicolumn{7}{|c|}{ II. MAE as the evaluation criterion } \\
\hline $\operatorname{GARCH}(1,1)$ & $0.0658(4)$ & $0.0697(4)$ & $0.0740(4)$ & $0.0790(4)$ & $0.0843(4)$ & $0.0892(4)$ \\
\hline $\operatorname{EGARCH}(1,1)$ & $0.1073(6)$ & $0.5461(6)$ & $0.8625(6)$ & $0.9614(5)$ & $0.9865(5)$ & $0.9926(5)$ \\
\hline SV & $0.0606(3)$ & $0.0601(3)$ & $0.0599(3)$ & $0.0622(3)$ & $0.0650(3)$ & $0.0678(3)$ \\
\hline FIGARCH $(1,1)$ & $0.0538(2)$ & $0.0519(2)$ & $0.0492(2)$ & $0.0485(2)$ & $0.0463(2)$ & $0.0435(2)$ \\
\hline FIEGARCH $(1,1)$ & $0.0935(5)$ & $0.5168(5)$ & $0.8606(5)$ & $0.9851(6)$ & $1.0196(6)$ & $1.0271(6)$ \\
\hline $\operatorname{ARFIMA}(1, \mathrm{~d}, 1)$ & $0.0530(1)$ & $0.0502(1)$ & $0.0474(1)$ & $0.0462(1)$ & $0.0456(1)$ & $0.0426(1)$ \\
\hline
\end{tabular}

Panel B: historical volatility (HV) as proxy

I. RMSE as the evaluation criterion

$\begin{array}{lllllll}\text { GARCH }(1,1) & 0.0030(4) & 0.0038(4) & 0.0048(4) & 0.0056(4) & 0.0066(4) & 0.0075(4) \\ \text { EGARCH }(1,1) & 0.0126(6) & 0.2993(6) & 0.7449(6) & 0.9252(5) & 0.9743(5) & 0.9862(5) \\ \text { SV } & 0.0025(3) & 0.0026(3) & 0.0032(3) & 0.0036(3) & 0.0041(2) & 0.0046(3) \\ \text { FIGARCH }(1,1) & 0.0018(2) & 0.0020(2) & 0.0022(2) & 0.0025(2) & 0.0029(1) & 0.0030(2) \\ \text { FIEGARCH(1,1) } & 0.0099(5) & 0.2682(5) & 0.7416(5) & 0.9714(6) & 1.0406(6) & 1.0559(6) \\ \text { ARFIMA(1,d,1) } & 0.0014(1) & 0.0019(1) & 0.0023(1) & 0.0024(1) & 0.0028(1) & 0.0029(1)\end{array}$


II. MAE as the evaluation criterion

$\begin{array}{lllllll}\text { GARCH }(1,1) & 0.0492(4) & 0.0564(4) & 0.0650(4) & 0.0714(4) & 0.0774(4) & 0.0830(4) \\ \text { EGARCH }(1,1) & 0.1109(6) & 0.5469(6) & 0.8630(6) & 0.9619(5) & 0.9871(5) & 0.9931(5) \\ \text { SV } & 0.0436(3) & 0.0427(3) & 0.0480(3) & 0.0520(3) & 0.0569(3) & 0.0611(3) \\ \text { FIGARCH(1,1) } & 0.0374(2) & 0.0400(2) & 0.0443(2) & 0.0465(2) & 0.0501(2) & 0.0510(2) \\ \text { FIEGARCH(1,1) } & 0.0976(5) & 0.5177(5) & 0.8611(5) & 0.9856(6) & 1.0201(6) & 1.0276(6) \\ \text { ARFIMA(1,d,1) } & 0.0326(1) & 0.0377(1) & 0.0423(1) & 0.0458(1) & 0.0490(1) & 0.0499(1)\end{array}$

Notes: This table evaluates the performance of different models in the forecasting of REIT volatility based on subsample II (06/08/2002-05/11/2006). The forecast period is $05 / 11 / 2005$ to $05 / 11 / 2006$ and a fixed rolling window of 736 observations is used. RMSE is root mean square error. MAE is mean absolute error. The numbers in parentheses are the relative ranking of each model for the corresponding evaluation criterion.

Table 7 Evaluations of REIT volatility forecasts based on subsample III

\begin{tabular}{|c|c|c|c|c|c|c|}
\hline \multirow[b]{2}{*}{ Models } & \multicolumn{6}{|c|}{ Forecast Horizons } \\
\hline & 1-day & 5-day & 10-day & 15-day & 20-day & 25-day \\
\hline
\end{tabular}

Panel A: realized volatility (RV) as proxy

I. RMSE as the evaluation criterion

\begin{tabular}{|c|c|c|c|c|c|c|}
\hline $\operatorname{GARCH}(1,1)$ & $0.0074(4)$ & $0.0141(4)$ & $0.0141(4)$ & $0.0143(3)$ & $0.0154(4)$ & $0.0161(4)$ \\
\hline $\operatorname{EGARCH}(1,1)$ & $0.2356(6)$ & $0.9876(5)$ & $0.9837(5)$ & $0.9833(5)$ & $0.9831(5)$ & $0.9829(5)$ \\
\hline SV & $0.0062(3)$ & $0.0101(3)$ & $0.0126(3)$ & $0.0143(3)$ & $0.0139(3)$ & $0.0139(3)$ \\
\hline FIGARCH $(1,1)$ & $0.0052(2)$ & $0.0055(2)$ & $0.0061(2)$ & $0.0065(2)$ & $0.0067(2)$ & $0.0069(2)$ \\
\hline FIEGARCH $(1,1)$ & $0.1137(5)$ & $1.5721(6)$ & $1.1275(6)$ & $1.1469(6)$ & $1.1186(6)$ & $1.1048(6)$ \\
\hline $\operatorname{ARFIMA}(1, \mathrm{~d}, 1)$ & $0.0047(1)$ & $0.0053(1)$ & $0.0058(1)$ & $0.0060(1)$ & $0.0061(1)$ & $0.0062(1)$ \\
\hline \multicolumn{7}{|c|}{ II. MAE as the evaluation criterion } \\
\hline $\operatorname{GARCH}(1,1)$ & $0.0793(4)$ & $0.1034(4)$ & $0.1283(4)$ & $0.1182(4)$ & $0.1224(4)$ & $0.1256(4)$ \\
\hline $\operatorname{EGARCH}(1,1)$ & $0.4821(6)$ & $0.9938(5)$ & $0.9918(5)$ & $0.9916(5)$ & $0.9916(5)$ & $0.9914(5)$ \\
\hline SV & $0.0726(3)$ & $0.0965(3)$ & $0.1094(3)$ & $0.1174(3)$ & $0.1162(3)$ & $0.1162(3)$ \\
\hline FIGARCH(1,1) & $0.0661(2)$ & $0.0682(2)$ & $0.0724(2)$ & $0.0757(2)$ & $0.0778(2)$ & $0.0792(2)$ \\
\hline $\operatorname{FIEGARCH}(1,1)$ & $0.3085(5)$ & $1.2527(6)$ & $1.0618(6)$ & $1.0709(6)$ & $1.0576(6)$ & $1.0511(6)$ \\
\hline $\operatorname{ARFIMA}(1, \mathrm{~d}, 1)$ & $0.0622(1)$ & $0.0660(1)$ & $0.0687(1)$ & $0.0717(1)$ & $0.0738(1)$ & $0.0754(1)$ \\
\hline
\end{tabular}

Panel B: historical volatility (HV) as proxy

I. RMSE as the evaluation criterion

$\begin{array}{lllllll}\text { GARCH }(1,1) & 0.0040(4) & 0.0079(4) & 0.0101(4) & 0.0112(4) & 0.0126(4) & 0.0140(4) \\ \text { EGARCH(1,1) } & 0.2386(6) & 0.9907(5) & 0.9867(5) & 0.9862(5) & 0.9856(5) & 0.9849(5) \\ \text { SV } & 0.0031(3) & 0.0065(3) & 0.0090(3) & 0.0110(3) & 0.0111(3) & 0.0118(3) \\ \text { FIGARCH }(1,1) & 0.0025(2) & 0.0023(2) & 0.0028(2) & 0.0034(2) & 0.0040(2) & 0.0049(2) \\ \text { FIEGARCH(1,1) } & 0.1164(5) & 1.5752(6) & 1.1305(6) & 1.1498(6) & 1.1211(6) & 1.1067(6) \\ \text { ARFIMA(1,d,1) } & 0.0013(1) & 0.0016(1) & 0.0020(1) & 0.0029(1) & 0.0037(1) & 0.0046(1)\end{array}$


II. MAE as the evaluation criterion

\begin{tabular}{lllllll} 
GARCH $(1,1)$ & $0.0576(4)$ & $0.0870(4)$ & $0.10434)$ & $0.1055(4)$ & $0.1118(4)$ & $0.1176(4)$ \\
EGARCH(1,1) & $0.4852(6)$ & $0.9953(5)$ & $0.9933(5)$ & $0.9931(5)$ & $0.9928(5)$ & $0.9924(5)$ \\
SV & $0.0512(3)$ & $0.0790(3)$ & $0.0943(3)$ & $0.1044(3)$ & $0.1049(3)$ & $0.1074(3)$ \\
FIGARCH(1,1) & $0.0444(2)$ & $0.0438(2)$ & $0.0479(2)$ & $0.0534(2)$ & $0.0598(2)$ & $0.0658(2)$ \\
FIEGARCH(1,1) & $0.3134(5)$ & $1.2539(6)$ & $1.0633(6)$ & $1.0723(6)$ & $1.0588(6)$ & $1.0520(6)$ \\
ARFIMA(1,d,1) & $0.0328(1)$ & $0.0363(1)$ & $0.0406(1)$ & $0.0479(1)$ & $0.0550(1)$ & $0.0620(1)$ \\
\hline
\end{tabular}

Notes: This table evaluates the performance of different models in the forecasting of REIT volatility based on subsample III (05/12/2006-04/30/2008). The forecast period is 05/01/2007 to 04/11/2008 and a fixed rolling window of 251 observations is used. RMSE is root mean square error. MAE is mean absolute error. The numbers in parentheses are the relative ranking of each model for the corresponding evaluation criterion.

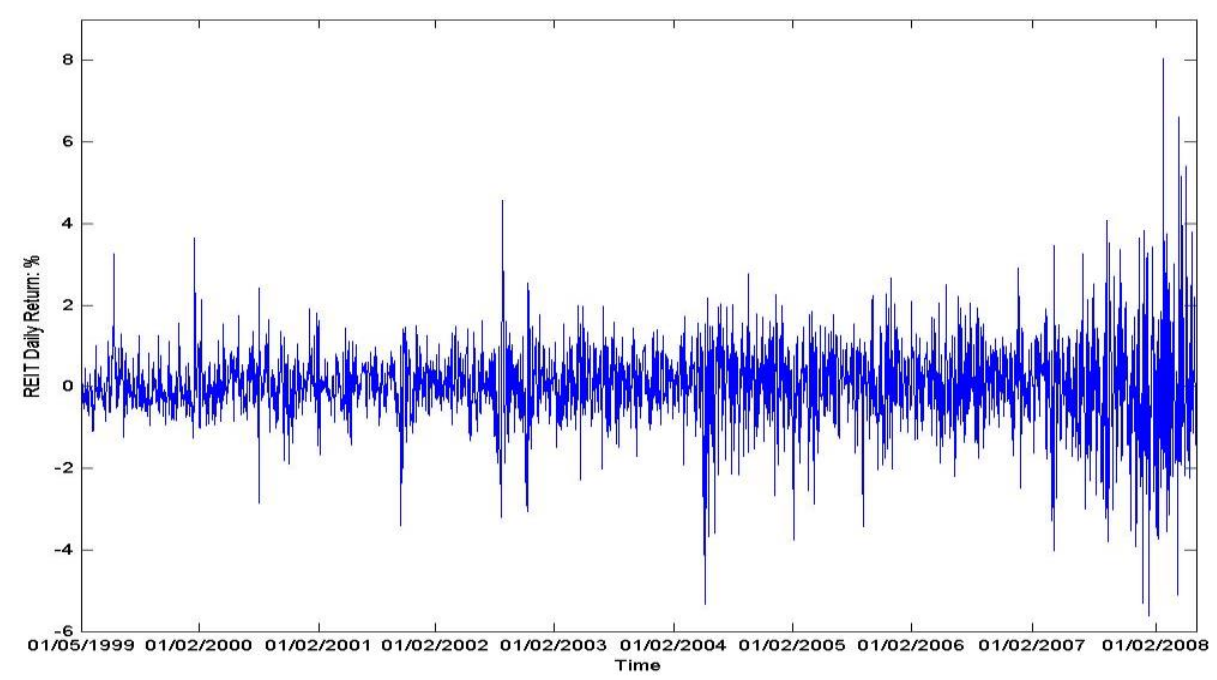

Figure 1 Time series plot of REIT daily returns for 01/05/1999 to 04/30/2008 


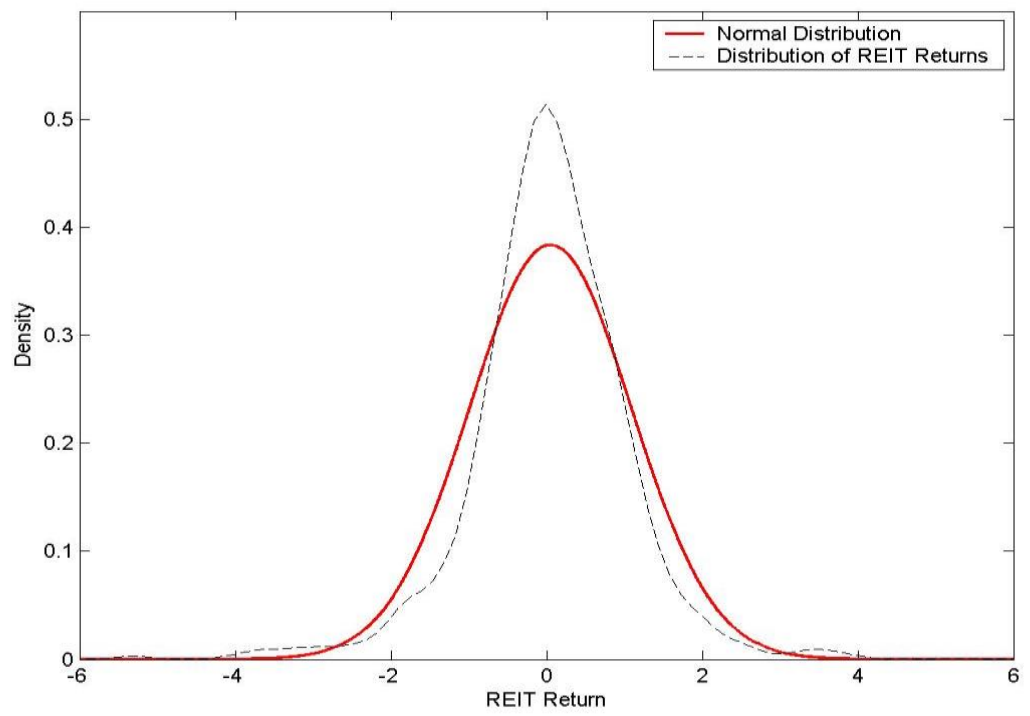

Figure 2 A comparison of the distribution of REIT daily returns with the normal distribution 